\title{
Effectiveness and Persistence with Liraglutide Among Patients with Type 2 Diabetes in Routine Clinical Practice-EVIDENCE: A Prospective, 2-Year Follow-Up, Observational, Post-Marketing Study
}

\author{
Jean-Francois Gautier • Luc Martinez • Alfred Penfornis • \\ Eveline Eschwège · Guillaume Charpentier • Benoît Huret · \\ Suliya Madani · Pierre Gourdy \\ To view enhanced content go to www.advancesintherapy.com \\ Received: August 10, 2015 / Published online: September 30, 2015 \\ (c) The Author(s) 2015. This article is published with open access at Springerlink.com
}

\begin{abstract}
Introduction: The aim of this study was to investigate whether the efficacy of liraglutide observed in randomized controlled trials translates into therapeutic benefits in the French population during routine clinical practice.
\end{abstract}

Methods: This observational, prospective, multicenter study included 3152 adults with

Electronic supplementary material The online version of this article (doi:10.1007/s12325-015-0245-x) contains supplementary material, which is available to authorized users.

J.-F. Gautier

Saint-Louis Hospital, Paris, France

L. Martinez

Université Pierre and Marie Curie, Paris, France

A. Penfornis - G. Charpentier

Centre Hospitalier Sud Francilien, Corbeil-Essonnes,

France

E. Eschwège

INSERM, Villejuif, France

B. Huret $\cdot$ S. Madani

Novo Nordisk, Paris, France

P. Gourdy ( $\square)$

Service de Diabétologie, CHU Rangueil, Toulouse,

France

e-mail: pierre.gourdy@inserm.fr type 2 diabetes who had recently started or were about to start liraglutide treatment. During 2 years of follow-up, an evaluation of the reasons for prescribing liraglutide, maintenance dose of liraglutide, changes in combined antidiabetic treatments, level of glycemic control, change in body weight and body mass index (BMI), patient satisfaction with diabetes treatment and safety of liraglutide were investigated. The primary study endpoint was the proportion of patients still receiving liraglutide and presenting with $\mathrm{HbA}_{1 \mathrm{c}}<7.0 \%$ after 2 years of follow-up.

Results: At the end of the study, 29.5\% of patients maintained liraglutide treatment and reached the $\mathrm{HbA}_{1 \mathrm{c}}$ target. Mean $( \pm \mathrm{SD}) \mathrm{HbA}_{1 \mathrm{c}}$, fasting plasma glucose concentration, body weight and BMI were significantly reduced from baseline $[8.46 \%( \pm 1.46)$ to $7.44 \%$ $( \pm 1.20) ; 180( \pm 60)$ to $146( \pm 44) \mathrm{mg} / \mathrm{dL} ; 95.2$ $( \pm 20.0)$ to $91.1( \pm 19.6) \mathrm{kg} ; 34.0( \pm 7.2)$ to 32.5 $( \pm 6.9) \mathrm{kg} / \mathrm{m}^{2} ;$ respectively, all $\left.P<0.0001\right]$. Patient treatment satisfaction increased, with the mean diabetes treatment satisfaction questionnaire status version score increasing from $22.17( \pm 7.64)$ to $28.55( \pm 5.79), P<0.0001$. The main adverse event type was 
gastrointestinal, with a frequency of $10.9 \%$, and the percentage of patients suffering $\geq 1$ hypoglycemic episode decreased from $6.9 \%$ to $4.4 \%$.

Conclusion: The results of the EVIDENCE study suggest that the effectiveness of liraglutide in real-world clinical practice is similar to that observed in randomized controlled trials.

Funding: Novo Nordisk A/S.

Trial Registration: ClinicalTrials.gov identifier, NCT01226966.

Keywords: BMI; Liraglutide; Observational; Type 2 diabetes; Weight

\section{INTRODUCTION}

Randomized controlled trials (RCTs) represent the reference standard in terms of assessing the efficacy and safety of any therapeutic agent, including glucagon-like peptide-1 receptor agonists (GLP-1RAs) such as liraglutide, which are considered in the American Diabetes Association/European Association for the Study of Diabetes 2015 position statement [1]. The results of the Liraglutide Effect and Action in Diabetes (LEAD) program demonstrated the anti-hyperglycemic efficacy of liraglutide as monotherapy and combined with other agents in the treatment of patients with type 2 diabetes (T2D) in RCTs. Furthermore, the LEAD program highlighted the low risk of hypoglycemia associated with liraglutide and the additional benefit of clinically relevant weight loss and decreased systolic blood pressure [2-8].

Observational studies are important to explore how treatments, such as liraglutide, are used in a real-life setting. Real-life data provide crucial information to evaluate the effectiveness of therapeutics in clinical practice and are being requested more and more frequently by health authorities. The Association of British Clinical Diabetologists $(\mathrm{ABCD})$ conducted a nationwide audit in the UK to assess the safety and effectiveness of liraglutide in real-life clinical practice. Data from this audit demonstrated that, after 6 months of treatment, liraglutide $1.2 \mathrm{mg}$ was effective in terms of reducing $\mathrm{HbA}_{1 \mathrm{c}}$ (more so in individuals with a higher baseline $\mathrm{HbA}_{1 \mathrm{c}}$ ) and well tolerated $[9,10]$. Furthermore, data from the IMS Health integrated claims database in the USA demonstrate that, in clinical practice, liraglutide (once daily) has greater effectiveness [in terms of $\mathrm{HbA}_{1 \mathrm{c}}$ reduction and improved glycemic goal attainment $\left.\left(\mathrm{HbA}_{1 \mathrm{c}}<7.0 \%\right)\right]$ compared with either exenatide (GLP-1RA, twice daily) or sitagliptin [dipeptidyl peptidase-4 (DPP-4) inhibitor, once daily] in patients with T2D [11].

Following liraglutide's approval in France by the European Medicines Agency (EMA) in July 2009, the French Health Authority (FHA) requested the current study with 2 years of follow-up to evaluate conditions for prescription, maintenance dose, effectiveness, and safety of this therapy in routine clinical practice.

\section{METHODS}

\section{Study Design}

This observational, prospective, multicenter study was conducted (during the period September 2010 to November 2013) in adults with T2D who were starting treatment with liraglutide in mainland France. Study physicians (endocrinologists and general practitioners), already treating patients with 
diabetes and prescribing injectable antidiabetic treatments were randomly recruited (by a contract research organization not connected to the survey sponsor) from the Centre de Gestion, de Documentation, d'Informatique et de Marketing (CEGEDIM) database and asked to include the first two or three consecutive patients meeting the eligibility criteria. Data were collected by physicians during routine care at inclusion (visit 1), then at approximately 3 months (visit 2), 6 months (visit 3), 12 months (visit 4), 18 months (visit 5), and 24 months (visit 6). Starting dose of liraglutide (0.6 mg/day), administration of liraglutide, and precautions for use were in accordance with the liraglutide summary of product characteristics (SmPC) [12]. This study was conducted in accordance with Good Pharmacoepidemiology Practices, the requirements in the Declaration of Helsinki and local legal requirements, the Consultative Committee on Information Processing in Health Research, and the National Committee of Data Processing and Freedom.

\section{Patients}

Patient recruitment took place from September 23, 2010 to November 15, 2011. Eligibility criteria for study inclusion were: age $\geq 18$ years, diagnosed with T2D, recently started (for less than 1 week) or starting (prescribed during visit 1) liraglutide and ability to provide written consent and complete a diabetes treatment satisfaction questionnaire (DTSQ). Exclusion criteria were any of the following: hypersensitivity to liraglutide or to any of the excipients, already participating in a clinical trial at inclusion, high probability to be lost to follow-up, or diagnosed with type 1 diabetes (T1D).

\section{Outcome Measures}

The primary endpoint of the study was the percentage of patients still taking liraglutide and having $\mathrm{HbA}_{1 \mathrm{c}}<7.0 \%$ at 2 years of follow-up. Secondary endpoints included, at each visit: an evaluation of the reasons for prescription of liraglutide, maintenance dose of liraglutide, changes in combined antidiabetic treatments, level of glycemic control [change in $\mathrm{HbA}_{1 \mathrm{c}}$ and fasting plasma glucose (FPG) concentration], change in body weight and body mass index (BMI), patient satisfaction with diabetes treatment, and safety of liraglutide [hypoglycemic episodes, adverse events (AEs), and medical events of special interest (MESI)]. Hypoglycemic episodes were investigated with the question, "Did the patient suffer one or more hypoglycemic episode (symptomatic or not) documented (by the physician during the visit) since the last visit or within four weeks of the visit?", but the design of the study did not include any hypoglycemia verification test. Hypoglycemic episodes were classified as minor (not requiring third-party intervention) or major/severe (requiring third-party intervention to administer carbohydrates, glucagon, or another emergency treatment). MESI included pathologies such as pancreatitis, thyroid gland anomalies, malignant neoplasias, and major hypoglycemic episodes.

\section{Study Populations for Specific Analyses}

\section{Full Analysis Set}

The population in the full analysis set (FAS) included all patients having attended the inclusion visit and for whom liraglutide was prescribed. The objectives evaluated with this data set were the characteristics of patients at inclusion and the prescribing conditions, the 
maintenance dose, and the safety (as requested by the FHA) at each visit.

\section{Effectiveness Analysis Set}

The population in the effectiveness analysis set (EAS) included all patients already included in the FAS and having completed the 2-year final visit under treatment with liraglutide and with at least one measurement of $\mathrm{HbA}_{1 \mathrm{c}}$, FPG, body weight, or hypoglycemia information at the end of the study. Some patients (20 in total) had thoroughly completed the 2 years of follow-up, though the physician filled an end of study form out with a reason for withdrawal from study. These patients were also included in the EAS population. The objectives evaluated with this data set were changes in $\mathrm{HbA}_{1 \mathrm{c}}$, FPG concentration, body weight, and BMI at each visit.

\section{Population for Primary Endpoint Analysis}

The population for the primary endpoint analysis (PEA) included all EAS patients plus patients who discontinued liraglutide treatment but remained in the study. The purpose of this pre-specified population was to prevent loss of data from patients who discontinued liraglutide before 2 years of follow-up.

\section{Patient-Reported Outcomes Analysis Set}

The population for the patient-reported outcomes set (PROAS) included all patients in the FAS who also filled in at least one item on the patient questionnaire at the inclusion visit and at least one follow-up visit. The DTSQs (status version) (satisfaction with treatment at each visit, which has a minimum score of zero and a maximum score of 36) and DTSQc (change version) (change in satisfaction with treatment between inclusion and 12 months, which has a minimum score of -18 and a maximum score of 18) were analyzed using the PROAS. Change in satisfaction with treatment was measured at 12 months due to the high number of missing data, with regard to this parameter, at 24 months.

\section{Missing Data}

No replacement of missing data was planned as part of the analysis of the primary endpoint.

\section{Statistical Analysis}

Calculating the sample size was based on the expected accuracy for the confidence interval (CI) of the number of patients still under treatment with $\mathrm{HbA}_{1 \mathrm{c}}<7.0 \%$ at 2 years. This calculation was based on an observed proportion of $40.0 \%$ not accessible for the primary endpoint based on a previous non-interventional study conducted by Novo Nordisk [13]. A sample size of 1707 patients would be adequate to achieve the goal with $\pm 2.5 \% \quad$ accuracy, the proportions observed with a significance of $95.0 \%$. Therefore, at least 2845 patients had to be recruited. For qualitative parameters, data are expressed as number of patients and percentages and as mean value \pm standard deviation (SD) for quantitative parameters. Quantitative parameters with normal distribution were analyzed by a Student test, otherwise by a non-parametric Wilcoxon-Mann-Whitney test, and qualitative parameters were analyzed by a Chi-square test with continuity correction or a Fisher's exact test if the hypothesis of the size of frequencies expected was not respected. If necessary, some ordinal levels were grouped. All tests were performed with a significance of 5.0\%. 


\section{RESULTS}

\section{Patient Disposition}

In total, 3590 patients with T2D were considered for inclusion. However, 438 patients were not included, mainly for the following reasons: patient refusal (36.0\%), miscellaneous reasons (31.0\%), well-controlled diabetes $(11.0 \%)$, or issues with compliance or irregular follow-up in consultation (10.0\%). In total, 1143 patients withdrew from the study early (before 2 years of follow-up) $-41.0 \%$ were lost to follow-up or moved and $21.8 \%$ withdrew due to AEs. The distribution of patients during the study is shown in Fig. 1.

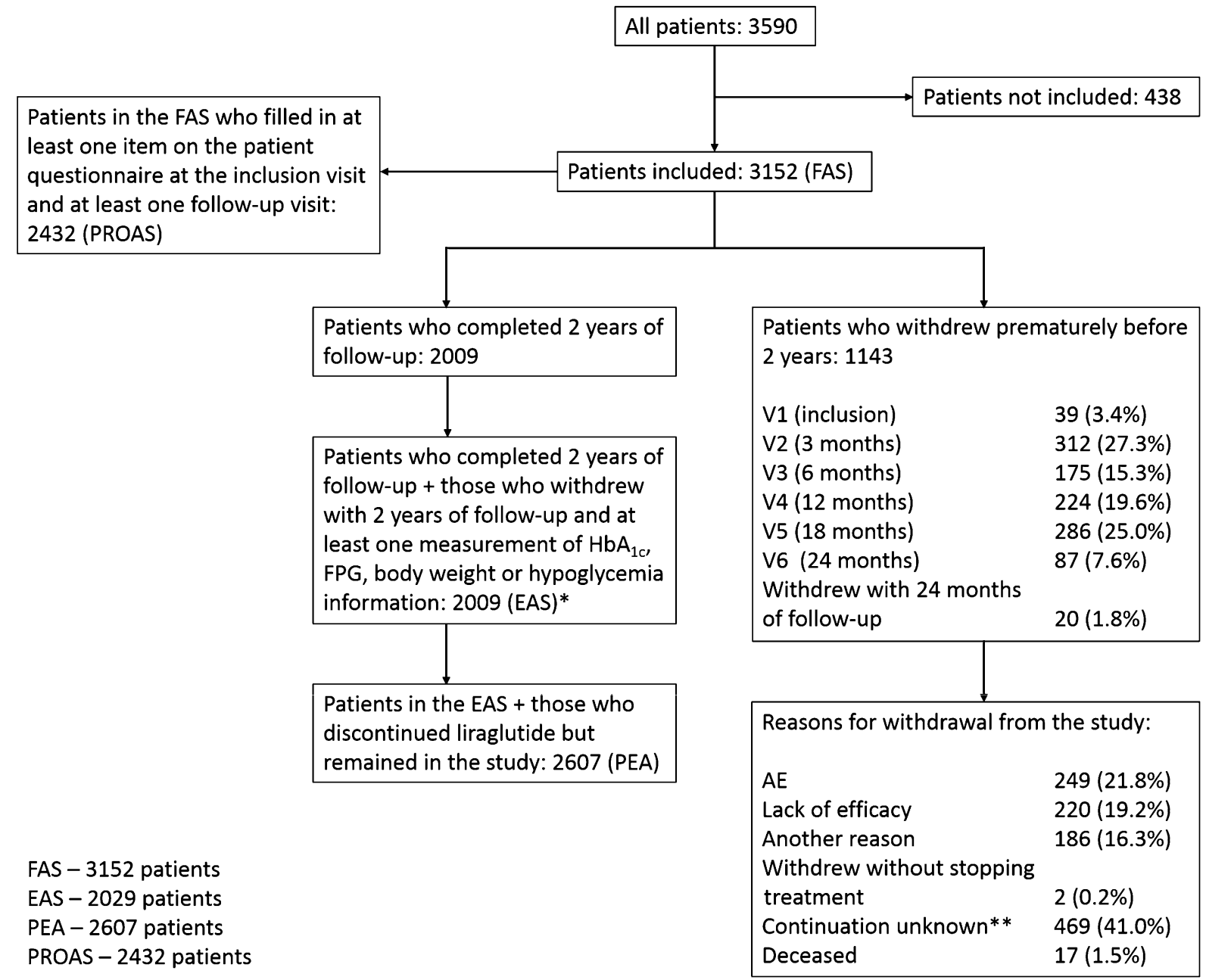

Fig. 1 Distribution of patients during the study. Asterisks some patients had thoroughly completed the 2 years of follow-up though the physician filled an end of study form out with a reason for withdrawal from study. These patients (20 in total) were included in the EAS population and counted as withdrawals from study. Double asterisks patients lost to follow-up or moved. $A E$ adverse event, $E A S$ effectiveness analysis set, $F A S$ full analysis set, $F P G$ fasting plasma glucose, $P E A$ population for primary endpoint analysis, PROAS patient-reported outcomes analysis set 


\section{Baseline Characteristics}

Baseline characteristics were collected from 3152 patients (FAS) enrolled in the EVIDENCE study and are shown in Table 1 . Motivations of physicians to prescribe liraglutide and the description of antidiabetic treatments before and at liraglutide initiation in the FAS are shown in Tables 2 and 3, respectively.

\section{Primary Endpoint}

In total, 769 of 2607 patients (29.5\%) in the PEA population maintained liraglutide treatment and reached the goal of $\mathrm{HbA}_{1 \mathrm{c}}<7.0 \%$ at the end of the study $(95.0 \%$ CI $27.7 ; 31.2)$, confirmed by the sensitivity analysis in the FAS population (3152 patients): $24.4 \%$ (95.0\% CI 22.9 ; 25.9).

\section{Secondary Endpoints}

\section{Evolution of Antidiabetic Treatment}

The most common reasons for prescribing liraglutide were desire for improvement of glycemic and weight control (Table 2). The evolution of antidiabetic treatment was analyzed using the EAS population (2029 patients). Liraglutide dose was initiated at $0.6 \mathrm{mg} /$ day and, by 3 months, the percentage of patients prescribed $1.2 \mathrm{mg} /$ day liraglutide had increased from $11.1 \%$ to $75.9 \%$. Patients who demonstrated inadequate glycemic control on the $1.2 \mathrm{mg} /$ day liraglutide dose were then transferred to the $1.8 \mathrm{mg} /$ day dose. At the end of the study, $49.1 \%$ and $45.5 \%$ of patients received $1.2 \mathrm{mg} /$ day or $1.8 \mathrm{mg} /$ day of liraglutide, respectively (Fig. 2). However, due to concerns with tolerability of the higher doses or observed efficacy with the $0.6 \mathrm{mg} /$ day dose, the remaining $5.4 \%$ of patients received
Table 1 Baseline characteristics of 3152 patients enrolled in the study-FAS

\begin{tabular}{lc}
\hline Characteristics & $\begin{array}{c}n(\%) \text { or mean } \\
( \pm \text { SD })\end{array}$ \\
\hline Age $(3146$ patients analyzed) & \\
Mean $( \pm$ SD), years & $58.7( \pm 10.5)$ \\
Gender (3152 patients analyzed) & \\
Male, $n$ (\%) & $1671(53.0)$ \\
Female, $n(\%)$ & $1481(47.0)$ \\
Followed by another physician ${ }^{\text {a }}$ (3147 patients analyzed) \\
Yes, $n$ (\%) \\
No, $n$ (\%) & $1717(54.6)$ \\
Social environment (3127 patients analyzed) & $1430(45.4)$ \\
Lives alone, $n$ (\%) & $621(19.9)$ \\
In family/couple, $n$ (\%) & $2497(79.9)$ \\
Retirement home, $n$ (\%) & $9(0.3)$
\end{tabular}

\section{Diabetes history}

Duration of diabetes (3140 patients analyzed)

$$
\text { Mean }( \pm S D) \text {, years } 9.7( \pm 6.7)
$$

Complication linked to diabetes ${ }^{\mathrm{b}}$ (3132 patients analyzed)

$$
\begin{array}{ll}
\text { Yes, } n(\%) & 1048(33.5) \\
\text { No, } n(\%) & 2084(66.5)
\end{array}
$$

If yes, type ${ }^{\mathrm{c}}$ (3131 patients analyzed)

Coronary disease, $n(\%) \quad 364$ (11.6)

Neuropathy, $n$ (\%) $277(8.8)$

Retinopathy, $n$ (\%) $252(8.0)$

Nephropathy, $n$ (\%) $\quad 240(7.7)$

Lower limb arteritis, $n$ (\%) $176(5.6)$

Cerebrovascular disease, $n$ (\%) $\quad 69(2.2)$

Diabetic foot, $n(\%) \quad 70(2.2)$

Other, $n$ (\%) $110(3.5)$

Clinical characteristics

Body weight (3151 patients analyzed)

Mean $( \pm S D), \mathrm{kg} \quad 95.6( \pm 19.9)$ 
Table 1 continued

\begin{tabular}{ll}
\hline Characteristics & $n(\%)$ or mean \\
& $( \pm \mathrm{SD})$ \\
\hline
\end{tabular}

BMI (3147 patients analyzed)

$$
\text { Mean }( \pm S D), \mathrm{kg} / \mathrm{m}^{2}
$$

BMI distribution (3147 patients analyzed)

$$
\begin{aligned}
& <18.5 \mathrm{~kg} / \mathrm{m}^{2}, n(\%) \\
& \geq 18.5 ;<25, n(\%) \\
& \geq 25 ;<30, n(\%) \\
& \geq 30 ;<40, n(\%) \\
& \geq 40 \mathrm{~kg} / \mathrm{m}^{2}, n(\%)
\end{aligned}
$$

Systolic blood pressure (3145 patients analyzed)

$$
\text { Mean }( \pm \mathrm{SD}), \mathrm{mmHg}
$$

Diastolic blood pressure (3144 patients analyzed)

$$
\text { Mean ( } \pm \text { SD), mmHg }
$$

\section{Biological characteristics}

$\mathrm{HbA}_{1 \mathrm{c}}$ (3109 patients analyzed)

$$
\text { Mean }( \pm S D), \%
$$

Fasting plasma glucose (2629 patients analyzed)

$$
\text { Mean }( \pm \mathrm{SD}), \mathrm{mmol} / \mathrm{L}
$$

Triglycerides (2701 patients analyzed)

$$
\text { Mean }( \pm S D), \mathrm{mmol} / \mathrm{L}
$$

High-density lipoprotein (2598 patients analyzed)

$$
\text { Mean }( \pm S D), \mathrm{mmol} / \mathrm{L}
$$

Low-density lipoprotein (2529 patients analyzed)

$$
\text { Mean ( } \pm S D), \mathrm{mmol} / \mathrm{L}
$$

$n$ number for subset, $S D$ standard deviation

a A patient may have been included in the study by a general practitioner but also managed by an endocrinologist

b All historical medical events were registered on the basis of patient reporting or their medical record

c Patients may have had more than one complication. Due to missing data, the $\%$ value relates to the number of patients analyzed within the FAS population for that particular characteristic and not the total FAS population
Table 2 Motivations that influenced the decision of physicians to prescribe liraglutide-FAS

\begin{tabular}{ll}
\hline Motivation & $\begin{array}{l}n / \text { total } \\
\text { analyzed (\%) }\end{array}$ \\
\hline Improvement of glycemic control & $2552 / 3145(81.1)$ \\
Reduction of hypoglycemic episodes & $290 / 3144(9.2)$ \\
Improvement of weight control & $2113 / 3145(67.2)$ \\
Potential beneficial effect on beta-cell & $915 / 3145(29.1)$ \\
$\quad$ function & $284 / 3143(9.0)$ \\
Improvement of blood pressure & $324 / 3145(10.3)$ \\
Adverse effect of current treatment & $578 / 3144(18.4)$ \\
Patient dissatisfaction with current & \\
treatment & $578 / 3144(18.4)$ \\
Trying a new treatment & $956 / 3144(30.4)$ \\
Potential beneficial effect of other & \\
\hline properties of GLP-1 &
\end{tabular}

Due to missing data, the \% value relates to the number of patients analyzed within the FAS population for that particular motivation and not the total FAS population. Physicians may have had more than one motivation for prescribing liraglutide

$F A S$ full analysis set, GLP-1 glucagon-like peptide-1, $n$ number for subset

$0.6 \mathrm{mg} /$ day liraglutide. Liraglutide was added to current antidiabetic therapy and, by the end of the study, there was a reduction in oral antidiabetic drug (OAD) monotherapy and an increase in the number of patients receiving more than three therapies in combination. Throughout the study, rates of prescription of biguanides, sulfonylureas (SUs), glinides, and alpha-glucosidase inhibitors remained stable. In contrast, prescriptions of DPP-4 inhibitors and glitazones fell from baseline to end of study (40.1\% to $9.7 \%$ and $14.1 \%$ to $3.0 \%$, respectively) and those of insulin increased from baseline to end of study (12.9\% to $24.0 \%$ ) (Table 3 ). 
Table 3 Change in antidiabetic treatment from before initiation of liraglutide to the end of study

\begin{tabular}{|c|c|c|c|c|c|}
\hline & $\begin{array}{l}\text { Before initiation } \\
\text { of liraglutide } \\
\text { (FAS) }\end{array}$ & $\begin{array}{l}\text { Before initiation } \\
\text { of liraglutide } \\
\text { (EAS) }\end{array}$ & $\begin{array}{l}\text { At end of } \\
\text { inclusion } \\
(0 \text { months }) \\
\text { (FAS) }\end{array}$ & $\begin{array}{l}\text { At end of } \\
\text { inclusion } \\
(0 \text { months }) \\
\text { (EAS) }\end{array}$ & $\begin{array}{l}\text { At end of study } \\
(2 \text { years }) \\
(\text { FAS/EAS })^{\mathbf{a}}\end{array}$ \\
\hline \multicolumn{6}{|l|}{ Therapeutic strategy } \\
\hline Monotherapy & $609(19.5)$ & $409(20.4)$ & $121(3.9)$ & $75(3.8)$ & $68(3.8)$ \\
\hline Double therapy & $1233(39.5)$ & $821(40.9)$ & $1181(38.2)$ & 795 (39.9) & $621(34.8)$ \\
\hline Triple therapy & $1090(34.9)$ & $667(33.2)$ & $1415(45.8)$ & $888(44.6)$ & $733(41.0)$ \\
\hline$>3$ triple therapy & $188(6.0)$ & $112(5.6)$ & $372(12.0)$ & $234(11.7)$ & $365(20.4)$ \\
\hline \multicolumn{6}{|l|}{ Treatments } \\
\hline Biguanides & $2561(82.1)$ & $1668(83.0)$ & $2521(81.6)$ & $1648(82.7)$ & $1623(82.5)$ \\
\hline SUs & $1780(57.1)$ & $1131(56.3)$ & $1596(51.6)$ & $992(49.7)$ & $1002(50.9)$ \\
\hline DPP-4 inhibitors & $1261(40.4)$ & $805(40.1)$ & $257(8.3)$ & $182(9.1)$ & $191(9.7)$ \\
\hline Insulin & $488(15.6)$ & $260(12.9)$ & $283(9.1)$ & $165(8.3)$ & $440(24.0)$ \\
\hline Glitazones & $425(13.6)$ & $284(14.1)$ & $190(6.1)$ & $121(6.1)$ & $60(3.0)$ \\
\hline Glinides & $277(8.9)$ & $158(7.9)$ & $221(7.1)$ & $124(6.2)$ & $172(8.7)$ \\
\hline Alpha-glucosidase inhibitors & $160(5.1)$ & $100(5.0)$ & $90(2.9)$ & $61(3.1)$ & $76(3.9)$ \\
\hline Total analyzed & $3120(100)$ & $2009(100)$ & $3089(100)$ & $1992(100)$ & $1787(100)$ \\
\hline
\end{tabular}

$D P P-4$ dipeptidyl peptidase-4, EAS effectiveness analysis set, $F A S$ full analysis set, $n$ number for subset, $S U$ Sulfonylurea

${ }^{a}$ There were the same number of patients still remaining in both FAS and EAS populations at the end of the study; therefore, the percentages are the same in both populations. Values are expressed as $n(\%)$. Due to missing data, the \% value relates to the number of patients analyzed within the FAS or EAS population for that particular time point and not the total FAS or EAS population

\section{Glycemic and Weight Control}

Changes in $\mathrm{HbA}_{1 \mathrm{c}}$, FPG concentration, body weight, and BMI from baseline to 2 years were analyzed using the EAS population. From baseline to end of study, mean $( \pm \mathrm{SD}) \mathrm{HbA}_{1 \mathrm{c}}$ was significantly $(P<0.0001)$ reduced [by $1.01 \% \quad( \pm 1.54)], \quad$ from $8.46 \%( \pm 1.46) \quad$ to $7.44 \%( \pm 1.20)$. At 2 years, $39.4 \%$ of the patients still on liraglutide maintained an $\mathrm{HbA}_{1 \mathrm{c}}<7.0 \%$. Mean FPG concentration [from $180( \pm 60)$ to $146( \pm 44) \mathrm{mg} / \mathrm{dL}]$, mean body weight [from $95.2( \pm 20.0)$ to $91.1( \pm 19.6) \mathrm{kg}$, and mean BMI [from $34.0( \pm 7.2)$ to 32.5 $\left.( \pm 6.9) \mathrm{kg} / \mathrm{m}^{2}\right]$ were also significantly (all $P<0.0001)$ reduced.

\section{Treatment Satisfaction}

Treatment satisfaction was analyzed in the PROAS population (2432 patients). Throughout the study, patient treatment satisfaction (with liraglutide) increased, with the DTSQs score increasing from a mean $( \pm \mathrm{SD})$ of $22.17( \pm 7.64)$ at baseline to $28.55( \pm 5.79)$ at end of study, $P<0.0001$. Change in satisfaction with treatment (compared with previous treatment) after 1 year of follow-up, measured 


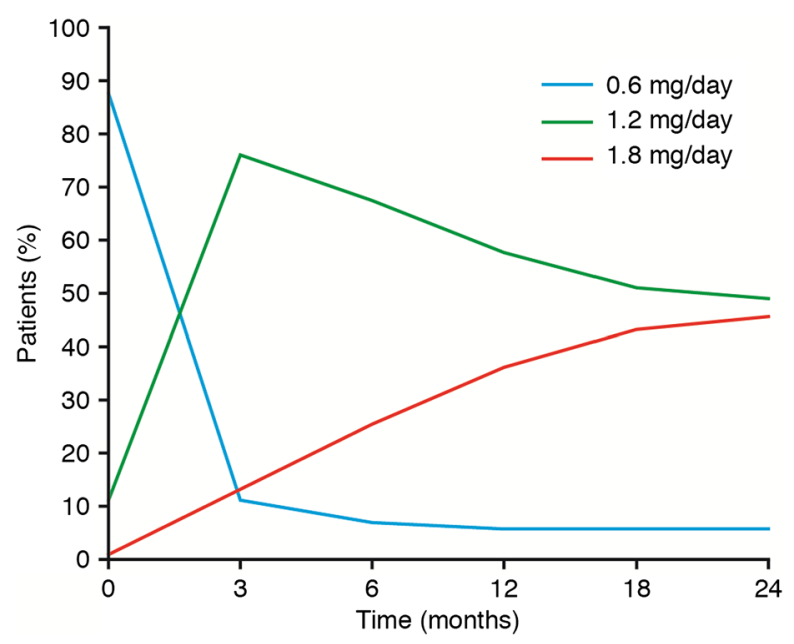

Fig. 2 Change in liraglutide dose by visits-EAS. EAS effectiveness analysis set

by the DTSQc, was, on average, $10.71( \pm 6.10)$ (95.0\% CI 10.39; 11.03).

\section{Hypoglycemia}

Hypoglycemic episodes were analyzed using the FAS population. The percentage of patients experiencing at least one hypoglycemic episode (in the 4 weeks preceding each visit) decreased during the study, from $7.4 \%$ at 3 months to $4.4 \%$ at end of study. Most episodes were minor, not requiring third-party intervention. Nine patients reported severe hypoglycemia during the 2-year study period. These patients were also being treated with either biguanides and SUs or insulin and glinides, and there was no correlation with liraglutide dose.

\section{AEs and MESI}

AEs were analyzed using the FAS population. In total, 653 patients $(20.7 \%)$ experienced at least one $\mathrm{AE}$ during the study period, with 458 patients (14.5\%) experiencing an AE possibly related to liraglutide. AE categories affecting at least $1.0 \%$ of the population are listed in Table 4. There were six serious AEs involving
Table 4 AE category affecting $\geq 1 \%$ of the populationFAS

\begin{tabular}{|c|c|}
\hline $\mathbf{A E}$ & $n(\%)$ \\
\hline GI & $345(10.9)$ \\
\hline Nausea & $144(4.6)$ \\
\hline Diarrhea & $63(2.0)$ \\
\hline Vomiting & $54(1.7)$ \\
\hline Dyspepsia & $51(1.6)$ \\
\hline Abdominal pain & $30(1.0)$ \\
\hline Constipation & $20(0.6)$ \\
\hline Upper abdominal pain & $19(0.6)$ \\
\hline Flatulence & $13(0.4)$ \\
\hline Gastro-esophageal reflux & $11(0.3)$ \\
\hline Metabolic and nutritional & $82(2.6)$ \\
\hline Hypoglycemia & $29(0.9)$ \\
\hline Inadequate control of diabetes & $17(0.5)$ \\
\hline Hyperglycemia & $10(0.3)$ \\
\hline Loss of appetite & $23(0.7)$ \\
\hline General & $73(2.3)$ \\
\hline Asthenia & $21(0.7)$ \\
\hline Lack of efficacy with treatment & $15(0.5)$ \\
\hline Medical and surgical procedures & $57(1.8)$ \\
\hline Hospitalization & $27(0.9)$ \\
\hline Cardiovascular disorders & $41(1.3)$ \\
\hline Atrial fibrillation & $10(0.3)$ \\
\hline Arrhythmia & $6(0.2)$ \\
\hline Myocardial infarction & $6(0.2)$ \\
\hline Coronary stenosis & $5(0.2)$ \\
\hline Central nervous system & $38(1.2)$ \\
\hline Neoplasias & $37(1.2)$ \\
\hline Prostate cancer & $5(0.2)$ \\
\hline Kidney cancer & $3(0.1)$ \\
\hline Squamous cell carcinoma & $2(0.1)$ \\
\hline
\end{tabular}

The safety population for AEs included all patients who had been prescribed liraglutide at least once and had at least one available safety data point after inclusion (3152 patients). The $n$ value relates to the number of AEs for each subset; the \% value relates to proportion of the FAS population affected

$A E$ adverse event, $F A S$ full analysis set, $G I$ gastrointestinal

digestive pathologies (one abdominal pain, two diarrhea, two nausea, and one vomiting). There were eight MESI related to pancreatic 
pathologies (two pancreatitis, four acute pancreatitis, one increased lipasemia, and one hepato-pancreatic biological disorder) and eight linked to thyroid pathologies (two goiters, one hyperthyroidism, one hypothyroidism, one thyroid disorder, one thyroid nodule, one thyroid cancer [non-encapsulated papillary carcinoma], and one thyroidectomy with no known etiology). During the study, 17 people died. However, a causal relationship to liraglutide was considered unlikely by the physicians for all causes of death except in one patient who died of a pancreatic tumor 4 months after starting treatment with liraglutide, and in another patient who died of a multifocal hepatocellular carcinoma 23 months after inclusion. In these cases, a causal relationship of these two events to liraglutide was considered possible by the physicians.

\section{DISCUSSION}

The EVIDENCE study was a prospective, observational study that aimed to assess conditions for prescription, maintenance dose, effectiveness, and safety of liraglutide in routine clinical practice in France. To minimize the limitations associated with the design of an observational study, physicians were chosen at random from a large sample and the number of patients recruited by each physician was limited to prevent a cluster effect. In total, 992 physicians at 992 sites in mainland France participated in the study. Therefore, this study can be considered representative of the national profile. Throughout the study, all contact between the sites and the sponsor went through the research organization to avoid bias in the delivery of routine care, and quality control was applied to each step of data handling, ensuring the correctness of all data, specifically regarding safety reporting. As this was an observational study, with no control group, the results are indicative of certain combinations and cannot give rise to cause-and-effect relationships. Furthermore, the complete data are not available for analysis for all patients, as any missing data were not replaced.

In the EVIDENCE study, the main motivation for physicians to prescribe liraglutide was to improve glycemic control. The studies in the LEAD program have shown that liraglutide may provide greater benefit when used earlier in the course of disease progression $[2,4]$. In the EVIDENCE study, only $\sim 20.0 \%$ of patients were receiving OAD monotherapy at the time of initiation of liraglutide. Additionally, compared with patients in the LEAD studies, patients included in the EVIDENCE study were slightly older (mean age 58.7 vs. $\sim 52.0$ to $\sim 58.0$ years) and more obese $(70.8 \%$ of patients had a BMI $\geq 30 \mathrm{~kg} / \mathrm{m}^{2}$ in the EVIDENCE study vs. $59.6 \%$ of patients across the six LEAD studies) [2-8, 14]. Taken together, this may suggest that liraglutide was initiated later in the disease course in the EVIDENCE study than in the LEAD studies. Indeed, the mean duration of diabetes for patients was 9.7 years in the EVIDENCE study and between 6.5 and 9.4 years in the LEAD studies [2-8]. One possible explanation for this is related to the guidelines available during the course of the EVIDENCE study that recommended the use of GLP-1RAs as second-line therapy [15]. Furthermore, $15.6 \%$ of patients were treated with insulin prior to liraglutide introduction in the EVIDENCE study, while this was not permitted in the LEAD studies [2-8], thus confirming that the EVIDENCE study included a different patient population compared with the LEAD studies. It is of note, however, that 
patients included in the EVIDENCE study had similarly poorly controlled diabetes (mean $\left.\mathrm{HbA}_{1 \mathrm{c}} 8.5 \%\right)$ to those in the LEAD studies (mean $\mathrm{HbA}_{1 \mathrm{c}}$ 8.1-8.6\%) [2-8].

Mean $\mathrm{HbA}_{1 \mathrm{c}}$ reduction, amounting to $-1.0 \%$, at the end of the EVIDENCE study, was clinically relevant and compared well with that in the LEAD RCTs $(-0.8 \%$ to $-1.5 \%)$ [2-8] and other real-world studies $(-0.9 \%$ to $-1.6 \%)$ [16-18]. Furthermore, liraglutide was associated with optimal glycemic control $\left(\mathrm{HbA}_{1 \mathrm{c}}<7.0 \%\right)$ in $\sim 30.0 \%$ of patients after 2 years of treatment, while only $9.8 \%$ of patients had $\mathrm{HbA}_{1 \mathrm{c}}<7.0 \%$ at baseline. The proportion of patients achieving optimal glycemic control in the EVIDENCE study is almost identical to results from a recent 26-week UK-based real-world study (29.3\%) [16] and only slightly below the $\sim 35.0 \%$ to $\sim 45.0 \%$ reported after 26 weeks of treatment in the LEAD RCTs, which shows liraglutide's effectiveness under standard conditions for use $[2-5,7,8]$. When comparing data from the EVIDENCE study with that from the LEAD-3 extension study (18 months in duration), a greater difference in patients achieving optimal glycemic control $\left(\mathrm{HbA}_{1 \mathrm{c}}<7.0 \%\right)$ is apparent, i.e., $\sim 30.0 \%$ in EVIDENCE vs. $\sim 53.0-58.0 \%$ in the LEAD-3 extension study [19]. However, it is possible that the proportion of patients achieving optimal glycemic control in the LEAD-3 extension study is influenced by survivor bias.

Real-world data demonstrate that most T2D patients starting GLP-1RA therapy have a high BMI [20], and previous studies have shown that liraglutide is associated with weight loss $[21,22]$. Moreover, a recent study showed that, across the LEAD studies, higher initial BMI was associated with slightly greater weight loss with liraglutide [14]. Therefore, unsurprisingly, the desire for improved weight control was an important motivation for physicians to prescribe liraglutide in the EVIDENCE study. In total, $95.2 \%$ of patients involved in the EVIDENCE study had a baseline BMI $\geq 25 \mathrm{~kg} / \mathrm{m}^{2}$ and, as reported in RCTs [2-8] and other real-world studies with liraglutide [16-18], the reductions in both weight and BMI seen throughout the EVIDENCE study were statistically significant. Although the impact of such weight loss in $\mathrm{T} 2 \mathrm{D}$ remains to be demonstrated in terms of prognosis, this trend may be enough to at least improve patient quality of life.

Throughout the study, the most commonly prescribed oral antidiabetic treatments remained stable with the introduction of liraglutide. However, there was a reduction in the use of DPP-4 inhibitors from $40.1 \%$ to $9.7 \%$. This may be expected, as data from an open-label extension study demonstrate the switch from DPP-4 inhibitor to liraglutide to be beneficial, both in terms of glycemic and weight control [23]. Moreover, liraglutide is not indicated for use in combination with DPP-4 inhibitors [12], and combinations of incretin-based therapies are not well studied to date and the theoretical benefits appear to be relatively limited [24]. Finally, it is not currently known whether there may be an increased risk of AEs when GLP-1RAs and DPP-4 inhibitors are used in combination. At the end of study, 191 patients were still being treated by a combination of liraglutide and a DPP-4 inhibitor. This may be interpreted as a lack of interaction between the sponsor and the physicians. Throughout the study, there was a reduction in the prescription of glitazones from $14.1 \%$ to $3.0 \%$. This observation may have been largely due to the withdrawal of these drugs from the French market during the study period and physicians' concerns regarding patients' weight. 
Patients initiating liraglutide treatment should be transferred from the starting dose of 0.6 to $1.2 \mathrm{mg} /$ day after at least 1 week [12]. This dose can then be increased further to $1.8 \mathrm{mg} /$ day for patients who require increased glycemic control. Consequently, at the end of study, about half of the study population were on the $1.2 \mathrm{mg} /$ day dose and half were on the $1.8 \mathrm{mg} /$ day dose. At the 12-month timepoint, $36.2 \%$ of patients were on the $1.8 \mathrm{mg} /$ day dose and about $58.0 \%$ were on $1.2 \mathrm{mg} /$ day. This finding compares well with results from a recent real-world study $(32.7 \%$ and $64.6 \%$, respectively) [17].

Throughout the study, even though the use of SUs and glinides remained stable and the use of insulin increased, the percentage of patients suffering at least one hypoglycemic episode (during the 4 weeks of preceding visits) decreased from $6.9 \%$ (baseline measure) to $4.4 \%$ and only nine patients experienced a severe hypoglycemic episode during the entire 2 years of follow-up. To put this into perspective, 11 patients experienced a severe hypoglycemic episode during the 4 weeks preceding inclusion in the study. All patients who experienced a severe hypoglycemic episode were also being treated with both biguanides and SUs or with insulin and glinides. Therefore, it is likely that liraglutide was not the cause of the severe hypoglycemic episodes, and data from the LEAD-3 trial demonstrated no cases of severe hypoglycemia when liraglutide was used as monotherapy [6]. However, with the lack of a control arm in the EVIDENCE study, it is difficult to conclusively evaluate this.

The most frequently reported AE type in this study was classified as belonging to gastrointestinal (GI) disorders, and the frequency reported (10.9\%) was similar to that reported in another real-world study (11.4\%) [17]. However, this occurrence is considerably lower than that observed with liraglutide in the LEAD RCTs $(\sim 33.0 \%$ to $\sim 56.0 \%)$ [2-8]. This may be due to the less controlled nature of safety reporting in this observational study which is a well-known phenomenon in non-RCTs [25]. However, it may also be possible that a prolonged dose escalation period in the EVIDENCE study may have contributed to this observation.

Based only on very limited data [26-30], some researchers have suggested that therapy with GLP-1RAs may increase the risk of pancreatitis [31, 32]. During this study, there were four cases $(0.1 \%)$ of acute pancreatitis, which is in agreement with the current SmPC for liraglutide $(<0.2 \%)$ [12]. The incidence of acute pancreatitis in this study was 0.8 cases per 1000 patient-years, which compares well with a rate of 1.6 cases per 1000 patient-years reported in a recent meta-analysis of 18 clinical trials involving liraglutide [33], and is less than the background incidence (4.2 cases per 1000 patient-years) in people with T2D [34]. This finding also relates well to another recent study, which suggests that the use of incretin-based drugs appears not to be associated with an increased risk of acute pancreatitis [35]. However, vigilance still needs to be conducted, as a recently published analysis suggests that, compared with other anti-hyperglycemic agents, use of incretin-based drugs is associated with an increased risk of reported pancreatitis in France [36]. At present, neither the US Food and Drug Administration (FDA) nor the EMA have reached a final conclusion regarding a causal relationship between GLP-1RAs and pancreatitis or pancreatic cancer. However, both agencies do agree that assertions concerning a causal association between incretin-based drugs and pancreatic safety, as expressed recently in the scientific literature 
and in the media, are inconsistent with the current data [37]. Overall, the safety profile for this study is in accordance with what is reported in the SmPC for liraglutide [12] and does not, therefore, alter liraglutide's risk-benefit profile.

Finally, results from the EVIDENCE study show an increase in patients' treatment satisfaction after initiating liraglutide therapy in a real-world setting, and treatment satisfaction has been shown to be associated with increased adherence to treatment [38] and lower $\mathrm{HbA}_{1 \mathrm{c}}$ values [39, 40].

\section{CONCLUSIONS}

The results of the EVIDENCE study suggest that the effectiveness of liraglutide in real-world clinical practice is similar to that observed in RCTs, even though there were important demographic and clinical differences between the patient populations. In addition, the incidence of GI events was considerably lower in EVIDENCE than in RCTs. Overall, the results from this observational study suggest that treatment with liraglutide translates into therapeutic benefits for patients with T2D in routine clinical practice.

\section{ACKNOWLEDGMENTS}

This study and the article processing charges for this publication were sponsored by Novo Nordisk A/S. All named authors meet the International Committee of Medical Journal Editors (ICMJE) criteria for authorship for this manuscript, take responsibility for the integrity of the work as a whole, and have given final approval to the version to be published. The authors would like to thank all investigators, patients, and study coordinators involved in the EVIDENCE study and Watermeadow
Medical, UK, for providing medical writing and editorial assistance to the authors during the preparation of this manuscript, funded by Novo Nordisk.

In terms of prior presentation, abstracts/posters relating to this work have been presented previously at Perkumpulan Endokrinologi Indonesia-X Kongres Nasional PERKENI, the 74th and 75th Annual Scientific Sessions of the American Diabetes Association, the 49th and 50th Annual Meetings of the European Association for the Study of Diabetes, the 16th and 17th Annual Professional Conference and Annual Meetings of the Canadian Diabetes Association/CSEM, the Australian Diabetes Society and Australian Diabetes Educators Association 2014 meeting, the International Diabetes Federation 22nd World Diabetes Congress, and the Societe Francaise d'Endocrinologie 31st Annual Congress.

Disclosures. Jean-François Gautier has received honoraria for advisory boards or lectures from AstraZeneca, Bristol Myers Squibb, GlaxoSmithKline, Eli Lilly, Novartis, Novo Nordisk, Sanofi, and Servier, and research grants from Lilly and Sanofi. Luc Martinez has served as an advisor or consultant for Amgen Inc., Astra Zeneca Pharmaceuticals LP, GlaxoSmithKline, Ipsen, Lilly, Mayoly Spindler, Menarini, Novo Nordisk, Pfizer Inc., and Servier. Alfred Penfornis has received fees for consultancy, advisory boards, speaking, travel, or accommodation from Sanofi, Lilly, Takeda, Janssen, Novartis, MSD, Astra Zeneca, Abbott, Novo Nordisk, and Medtronic. Eveline Eschwège has no conflicts of interest to declare. Guillaume Charpentier has received lecture fees from Boehringer Ingelheim Pharmaceuticals, Bristol-Myers Squibb, Eli 
Lilly, Merck Sharp \& Dohme, Novo Nordisk, and Sanofi. He is a member of Advisory Boards of Janssen, J \& J, Medtronic, Novo Nordisk, and Sanofi. He has received research support from Abbott, Novartis, Novo Nordisk, Pfizer, and Sanofi. Benoît Huret works for Novo Nordisk and holds shares in the company. Suliya Madani works for Novo Nordisk and holds shares in the company. Pierre Gourdy has received consulting and lecture fees from AstraZeneca, Bristol Myers Squibb, Boehringer Ingelheim, Eli-Lilly, Janssen, Merck Sharp \& Dohme, Novartis, Novo Nordisk, Sanofi, and Takeda, and research grants from AstraZeneca and Sanofi.

Compliance with ethics guidelines. All procedures followed were in accordance with the ethical standards of the responsible committee on human experimentation (institutional and national) and with the Helsinki Declaration of 1964, as revised in 2013. Informed consent was obtained from all patients for being included in the study.

Open Access. This article is distributed under the terms of the Creative Commons Attribution-NonCommercial 4.0 International License (http://creativecommons.org/licenses/ by-nc/4.0/), which permits any noncommercial use, distribution, and reproduction in any medium, provided you give appropriate credit to the original author(s) and the source, provide a link to the Creative Commons license, and indicate if changes were made.

\section{REFERENCES}

1. Inzucchi SE, Bergenstal RM, Buse JB, et al. Management of hyperglycaemia in type 2 diabetes, 2015: a patient-centred approach. Update to a position statement of the American
Diabetes Association and the European Association for the Study of Diabetes. Diabetologia. 2015;58:429-42.

2. Marre $M$, Shaw J, Brandle $M$, et al. Liraglutide, a once-daily human GLP-1 analogue, added to a sulphonylurea over 26 weeks produces greater improvements in glycaemic and weight control compared with adding rosiglitazone or placebo in patients with type 2 diabetes (LEAD-1 SU). Diabet Med. 2009;26:268-78.

3. Zinman B, Gerich J, Buse JB, et al. Efficacy and safety of the human glucagon-like peptide-1 analog liraglutide in combination with metformin and thiazolidinedione in patients with type 2 diabetes (LEAD-4 Met + TZD). Diabetes Care. 2009;32:1224-30.

4. Nauck M, Frid A, Hermansen K, et al. Efficacy and safety comparison of liraglutide, glimepiride, and placebo, all in combination with metformin, in type 2 diabetes: the LEAD (liraglutide effect and action in diabetes)-2 study. Diabetes Care. 2009;32:84-90.

5. Buse JB, Rosenstock J, Sesti G, et al. Liraglutide once a day versus exenatide twice a day for type 2 diabetes: a 26-week randomised, parallel-group, multinational, open-label trial (LEAD-6). Lancet. 2009;374:39-47.

6. Garber A, Henry R, Ratner R, et al. Liraglutide versus glimepiride monotherapy for type 2 diabetes (LEAD-3 mono): a randomised, 52-week, phase III, double-blind, parallel treatment trial. Lancet. 2008;373:473-81.

7. Russell-Jones D, Vaag A, Schmitz O, et al. Liraglutide vs. insulin glargine and placebo in combination with metformin and sulfonylurea therapy in type 2 diabetes mellitus (LEAD-5 met $+\mathrm{SU}):$ a randomised controlled trial. Diabetologia. 2009;52:2046-55.

8. Croom KF, McCormack PL. Liraglutide: a review of its use in type 2 diabetes mellitus. Drugs. 2009;69:1985-2004.

9. Thong KY, Walton C, Ryder REJ. Safety and efficacy of liraglutide $1.2 \mathrm{mg}$ in patients with mild and moderate renal impairment: the ABCD nationwide liraglutide audit. Pract Diabetes. 2013;30:71-6.

10. Thong KY, Gupta PS, Cull ML, et al. GLP-1 receptor agonists in type 2 diabetes-NICE guidelines versus clinical practice. $\mathrm{Br} \mathrm{J}$ Diabetes Vasc Dis. 2014;14:52-9.

11. Lee WC, Dekoven M, Bouchard J, Massoudi M, Langer J. Improved real-world glycaemic outcomes with liraglutide versus other incretin-based 
therapies in type 2 diabetes. Diabetes Obes Metab. 2014;16:819-26.

12. Novo Nordisk. Liraglutide SmPC. http://www.ema. europa.eu/docs/en_GB/document_library/EPAR_-_ Product_Information/human/001026/WC5000500 17.pdf. Accessed 29 June 2015.

13. Marre M, Pinget $\mathrm{M}$, Gin $\mathrm{H}$, et al. Insulin detemir improves glycaemic control with less hypoglycaemia and no weight gain: 52-week data from the PREDICTIVE study in a cohort of French patients with type 1 or type 2 diabetes. Diabetes Metab. 2009;35:469-75.

14. Niswender K, Pi-Sunyer X, Buse J, et al. Weight change with liraglutide and comparator therapies: an analysis of seven phase 3 trials from the liraglutide diabetes development programme. Diabetes Obes Metab. 2013;15:42-54.

15. Nathan DM, Buse JB, Davidson MB, et al. Medical management of hyperglycemia in type 2 diabetes: a consensus algorithm for the initiation and adjustment of therapy: a consensus statement of the American Diabetes Association and the European Association for the Study of Diabetes. Diabetes Care. 2009;32:193-203.

16. Nyeland ME, Ploug UJ, Richards A, et al. Evaluation of the effectiveness of liraglutide and sitagliptin in type 2 diabetes: a retrospective study in UK primary care. Int J Clin Pract. 2015;69:281-91.

17. Buysschaert M, D'Hooge D, Preumont V, Roots Study Group. ROOTS: a multicenter study in Belgium to evaluate the effectiveness and safety of liraglutide (Victoza $\left({ }^{\circledR}\right)$ ) in type 2 diabetic patients. Diabetes Metab Syndr. 2015;9:139-42.

18. Mezquita-Raya P, Reyes-Garcia R, Moreno-Perez O, Escalada-San Martin J, Herrera MÁR, de la Torre Casares ML. Clinical effects of liraglutide in a real-world setting in Spain: eDiabetes-Monitor SEEN Diabetes Mellitus Working Group Study. Diabetes Ther 2015 6:173-85.

19. Garber A, Henry RR, Ratner R, et al. Liraglutide, a once-daily human glucagon-like peptide 1 analogue, provides sustained improvements in glycaemic control and weight for 2 years as monotherapy compared with glimepiride in patients with type 2 diabetes. Diabetes Obes Metab. 2011;13:348-56.

20. Hall GC, McMahon AD, Dain MP, Wang E, Home PD. Primary-care observational database study of the efficacy of GLP-1 receptor agonists and insulin in the UK. Diabet Med. 2013;30:681-6.

21. Shyangdan DS, Royle PL, Clar C, Sharma P, Waugh $\mathrm{N}$, Snaith A. Glucagon-like peptide analogues for type 2 diabetes mellitus: systematic review and meta-analysis. BMC Endocr Disord. 2010;9:10-20.

22. Vilsbøll $\mathrm{T}$, Christensen $\mathrm{M}$, Junker AE, Knop FK, Gluud LL. Effects of glucagon-like peptide-1 receptor agonists on weight loss: systematic review and meta-analyses of randomised controlled trials. BMJ. 2012;344:d7771.

23. Pratley RE, Nauck MA, Bailey T, et al. Efficacy and safety of switching from the DPP-4 inhibitor sitagliptin to the human GLP-1 analog liraglutide after 52 weeks in metformin-treated patients with type 2 diabetes: a randomized, open-label trial. Diabetes Care. 2012;35:1986-93.

24. Violante R, Oliveira JH, Yoon $\mathrm{KH}$, et al. A randomized non-inferiority study comparing the addition of exenatide twice daily to sitagliptin or switching from sitagliptin to exenatide twice daily in patients with type 2 diabetes experiencing inadequate glycaemic control on metformin and sitagliptin. Diabet Med. 2012;29:e417-24.

25. Hazell L, Shakir SA. Under-reporting of adverse drug reactions: a systematic review. Drug Saf. 2006;29:385-96.

26. Elashoff M, Matveyenko AV, Gier B, Elashoff R, Butler PC. Pancreatitis, pancreatic, and thyroid cancer with glucagon-like peptide-1-based therapies. Gastroenterology. 2011;141:150-6.

27. Singh S, Chang HY, Richards TM, Weiner JP, Clark JM, Segal JB. Glucagonlike peptide 1-based therapies and risk of hospitalization for acute pancreatitis in type 2 diabetes mellitus: a population-based matched case-control study. JAMA Intern Med. 2013;173:534-9.

28. Matveyenko AV, Dry S, Cox HI, et al. Beneficial endocrine but adverse exocrine effects of sitagliptin in the human islet amyloid polypeptide transgenic rat model of type 2 diabetes: interactions with metformin. Diabetes. 2009;58:1604-15.

29. Nachnani JS, Bulchandani DG, Nookala A, et al. Biochemical and histological effects of exendin- 4 (exenatide) on the rat pancreas. Diabetologia. 2010;53:153-9.

30. Gier B, Matveyenko AV, Kirakossian D, Dawson D, Dry SM, Butler PC. Chronic GLP-1 receptor activation by exendin- 4 induces expansion of pancreatic duct glands in rats and accelerates formation of dysplastic lesions and chronic pancreatitis in the $\operatorname{Kras}(\mathrm{G} 12 \mathrm{D})$ mouse model. Diabetes. 2012;61:1250-62.

31. Gale EA. GLP-1 based agents and acute pancreatitis: drug safety falls victim to the three monkey paradigm. BMJ. 2013;346:f1263. 
32. Gier B, Butler PC. Glucagonlike peptide 1-based drugs and pancreatitis: clarity at last, but what about pancreatic cancer? JAMA Intern Med. 2013;173:539-41.

33. Jensen TM, Saha K, Steinberg WM. Is there a link between liraglutide and pancreatitis? A post hoc review of pooled and patient-level data from completed liraglutide type 2 diabetes clinical trials. Diabetes Care. 2015;38:1058-66.

34. Noel RA, Braun DK, Patterson RE, Bloomgren GL. Increased risk of acute pancreatitis and biliary disease observed in patients with type 2 diabetes: a retrospective cohort study. Diabetes Care. 2009;32:834-8.

35. Thomsen RW, Pedersen L, Møller N, Kahlert J, Beck-Nielsen H, Sørensen HT. Incretin-based therapy and risk of acute pancreatitis: a nationwide population-based case-control study. Diabetes Care. 2015. doi:10.2337/dc13-2983.

36. Faillie JL, Babai S, Crépin S, et al. Pancreatitis associated with the use of GLP-1 analogs and DPP-4 inhibitors: a case/non-case study from the French Pharmacovigilance Database. Acta Diabetol. 2014;51:491-7.

37. Egan AG, Blind E, Dunder K, et al. Pancreatic safety of incretin-based drugs-FDA and EMA assessment. N Engl J Med. 2014;370:794-7.

38. Hendrychova T, Vytrisalova M, Smahelova A, Vlcek $\mathrm{J}$, Kubena AA. Adherence in adults with type 1 diabetes mellitus correlates with treatment satisfaction but not with adverse events. Patient Prefer Adherence. 2013;7:867-76.

39. Ken W, Koopmanschap MA, Stolk RP, Rutten GE, Wolffenbuttel BH, Niessen LW. Health-related quality of life and treatment satisfaction in Dutch patients with type 2 diabetes. Diabetes Care. 2002;25:458-63.

40. Bradley C, Lewis KS. Measures of psychological well-being and treatment satisfaction developed from the responses of people with tablet-treated diabetes. Diabet Med. 1990;7:445-51. 